\title{
SABERES DOCENTES SOBRE MEIO AMBIENTE EM UMA COMUNIDADE RIBEIRINHA DA AMAZÔNIA AMAPAENSE
}

\author{
Raimunda Kelly Silva Gomes ${ }^{1}$ \\ Luiza Nakayama ${ }^{2}$
}

\begin{abstract}
Resumo
O objetivo deste estudo foi compreender a percepção dos professores da Escola Estadual Francisco Filho, na Amazônia amapaense, sobre a educação ambiental numa vertente holística. Utilizamos a técnica de entrevistas semiestruturadas e de grupo focal, verificando que a maioria dos docentes é jovem, solteiro e tem ensino superior completo e, destes, $10 \%$ têm pósgraduação lato sensu, e, por esta razão, a maioria dos informantes atua no Ensino Fundamental II e/ou Ensino Médio. Embora a maioria apresente uma percepção romântica/naturalista de meio ambiente, contudo, demonstra conhecer os principais problemas ambientais locais, significando que, apesar de os professores terem uma visão fragmentada de meio ambiente, estão atentos ao cotidiano do alunado.
\end{abstract}

Palavras-chave: Saberes. Educação ambiental. Professores.

\section{TEACHERS' KNOWLEDGE OF ENVIRONMENT ON A RIVERSIDE COMMUNITY IN AMAPÁ AMAZON.}

\section{Abstract}

The aim of this study was to understand the perception the teachers of Francisco Filho State School, in Amapá Amazon, have of environmental education in a holistic dimension. We used the technique of semi-structured interviews and focus group, observing that most teachers are young, single and have completed higher education; of these, $10 \%$ have lato sensu graduation and, for this reason, most respondents teach in Elementary Education and/or high school. Although most teachers present a Romantic/Naturalist perception of the environment, they seem to know the main local environmental problems, which means that even though the teachers have a fragmented view of the subject, they are aware of their student's daily life.

Keywords: Knowledge. Environmental education. Teachers.

\section{SABERES DOCENTES SOBRE MEDIO AMBIENTE EN UNA COMUNIDAD RIBEIRINHA DE LA AMAZONIA AMAPAENSE}

\section{Resumen}

El objetivo de este estudio fue comprender la percepción de los profesores de la Escuela Estadual Francisco Filho, en la Amazonia amapaense, sobre la educación ambiental en una vertiente holística. Se utilizó la técnica de entrevistas semiestructuradas y de grupo focal, verificando que la mayoría de los docentes es joven, soltero y tiene una enseñanza superior

\footnotetext{
${ }^{1}$ Professora Adjunta da Universidade Estadual do Amapá. Grupo de Integração Socioambiental e Educacional (GISAE). End. Avenida Duque de Caixias,60, centro. Macapá-AP, Brasil. CEP: 68900-071. Email: rkellysgomes@yahoo.com.br

${ }^{2}$ Professora Adjunta da Universidade Federal do Pará, Campus Universitário do Guamá. Sala Verde Pororoca Espaço Interativo Socioambiental Paulo Freire. End. Rua Augusto Montenegro, 01, Guamá, Belém-PA, Brasil. CEP: 66075-110. Email: lunaka@ufpa.br
} 
completa y, de éstos, el $10 \%$ tiene postgrado lato sensu, y, por esta razón, la mayoría de los informantes actúa en la Enseñanza Fundamental II y / o Enseñanza Media. Aunque la mayoría presenta una percepción romántica / naturalista de medio ambiente, sin embargo, demuestra conocer los principales problemas ambientales locales, significando que, a pesar de que los profesores tienen una visión fragmentada de medio ambiente, están atentos a lo cotidiano del alumnado.

Palabras clave: Saberes. Educación ambiental. Profesores

\section{Introdução}

O fazer pedagógico que se almeja para a Educação Ambiental (EA) exige que o educador ambiental, posicione-se também cidadão - não apenas em sua vertente pedagógica, mas também política de sua intervenção, uma vez que a EA, como educação política, busca questionar as políticas atuais, associada a uma educação escolar, a qual transmite conteúdos científicos descontextualizados, com mera finalidade avaliativa. Nesse contexto, Leff (2010) considera que a EA deve assumir o desafio de abrir caminhos para um novo porvir, embasado em reflexões sobre o sentido da existência humana e as ressignificações para compreensão do mundo, da natureza e de suas culturas.

Nessa perspectiva, consideramos que a relação entre a forma como o professor constrói seus saberes e representações, e busca integrá-los em sua prática docente, pode servir de fundamento para entender e repensar a inserção da EA no ensino formal, bem como de ferramenta para avaliar as propostas institucionais efetivadas nesse campo.

Nesse contexto, Tuan (1980) ressalta a necessidade de se entender a percepção não apenas como resposta aos estímulos externos, mas também a atividade proposital, na qual alguns fenômenos são registrados enquanto outros são bloqueados. Assim, muito do que é percebido tem valor para as pessoas, de acordo com seus interesses, necessidades, visões de mundo e experiências vivenciadas.

No entanto, Reigota (2009) ressalta que o primeiro passo para que a Educação Ambiental (EA) seja efetivada no âmbito escolar é a sua correta construção do significado de meio ambiente, na qual devem ser considerados os aspectos naturais e sociais, assim como as relações entre os fatores biológicos, físicos, sociais, econômicos, históricos e culturais, e, aqui, também podemos destacar os aspectos cognitivos e afetivos do homem com o ambiente que o cerca.

Por outro lado, Miranda (2007) destaca que a percepção de ambiente no qual se vive pode ser entendida como primordial para a construção do conhecimento e da consciência ambiental, e uma maneira de se conhecer o real sentido dos conteúdos curriculares.

Portanto, consideramos que a percepção ambiental dos professores deve estabelecer conexões entre teoria e prática, além de permitir uma reflexão abrangente da realidade: uma tomada de consciência. Logo, o objetivo deste estudo foi compreender os saberes, as atitudes e valores apresentados pelos docentes, na comunidade de Anauerapucu - AP, localizada em uma comunidade ribeirinha da Amazônia amapaense.

\section{Materiais e métodos}

O município de Santana é considerado o segundo mais populoso do estado do Amapá, com uma população de aproximadamente 101.260 habitantes. O distrito de Anauerapucu está localizado na rodovia AP 070, o qual é um plano de assentamento agroextrativista do Instituto 
Nacional de Colonização e Reforma Agrária (Incra), com 235 domicílios (totalizando 998 habitantes) e estando à margem esquerda do rio Vila Nova, na divisa entre as bacias hidrográficas do rio Matapi e do rio Vila Nova (INSTITUTO BRASILEIRO DE GEOGRAFIA E ESTATÍSTICA, 2010). A Escola Estadual Francisco Filho, localizada no assentamento agroextrativista do Anauerapucu, oferece ensino fundamental $\left(1^{\circ}\right.$ ao $9^{\circ}$ ano $)$ e ensino médio, com um total de 286 alunos matriculados em 2015.

Quanto ao procedimento metodológico, este artigo fundamenta-se em um estudo de caso, por buscar a compreensão dos saberes da realidade específica da Escola Estadual Francisco Filho, e este contexto particular de assentamento pode, segundo Yin (2010), contribuir para o conhecimento dos fenômenos individuais, grupais, organizacionais e sociais da realidade existente. Em relação à abordagem selecionamos a pesquisa quali-quantitativa, pois ela permite, de acordo com Gunther (2006), a interpretação dos dados, descrever e analisar os fenômenos envolvidos no meio em que vivem. Além disso, Flick (2009) e Santos-Filho e Gamboa (2002) ressaltam que as evidências entre estas abordagens são complementares para compreensão holística dos fatos estudados.

Portanto, nesta pesquisa realizamos entrevistas semiestruturadas com todos os 22 professores atuantes na Escola Estadual Francisco Filho, com a finalidade de traçar o perfil socioeducativo docente e suas percepções sobre meio ambiente. Além disso, comparamos nossas observações diretas com algumas percepções dos docentes sobre os problemas ambientais.

Após a análise das entrevistas optamos pela utilização do método do grupo focal, que, como salientam Borges e Santos (2005) e Bellenger et al. (1976), é uma dentre as várias modalidades de grupo de discussão em que os participantes dialogam sobre uma temática, de forma espontânea e com maior envolvimento no debate. Nesse sentido, idealizamos os encontros, realizados entre abril a junho de 2015, com a finalidade de focalizar os pontos aos quais precisávamos ter uma visão mais aprofundada a respeito da percepção dos professores sobre meio ambiente. Destacamos que, de acordo com Andrade e Amorin (2010), a contribuição do grupo focal é entender como os sujeitos reagem a uma determinada temática num processo de interação grupal, fato que nos permitiu compreender os saberes docentes no decorrer do percurso metodológico, como um recurso para compreender o processo de construção das percepções, saberes e atitudes de determinados grupos sociais.

Para execução da técnica do grupo focal, dividimos os professores em dois grupos de trabalho composto por onze docentes cada, os quais se subdividiram espontaneamente. As sessões tiveram uma duração aproximada de duas horas cada, as quais foram transcritas na íntegra. Com as informações coletadas montamos uma base de dados usando o pacote estatístico SPSS (Statistical Package for the Social Sciences) versão 21.0.

\section{Resultados e discussão}

\subsection{Perfil socioeducativo dos docentes da Escola Estadual Francisco Filho}

Ao traçar o perfil socioeducativo docente, verificamos que $60 \%$ são do sexo feminino, fato corroborado por Gatti (2010), que chama atenção ao identificar que 75,4\% dos licenciandos brasileiros atualmente são do sexo feminino, ponderando que este fenômeno é mantido desde a criação das Escolas Normais, no final do século XIX, momento histórico em que as mulheres começaram a ser recrutadas para o magistério das primeiras letras, e sua escolarização em nível médio se deu por meio dos cursos de formação para o magistério (GATTI; BARRETO, 2009). Todavia, essa realidade vai se modificando à medida que se caminha da educação infantil para 
o ensino médio e técnico profissionalizante, pois a presença de professores do sexo masculino é marcante.

Destaca-se que na região Norte brasileira, o estado do Amazonas (31,33\%) e Amapá $(32,22 \%)$ contribuem com o maior número de atuação masculina na docência da educação básica (INSTITUTO NACIONAL DE ESTUDOS E PESQUISAS EDUCACIONAIS ANÍSIO TEIXEIRA, 2009). No entanto, percebemos que, no estado do Amapá, o número de professores do sexo masculino vem aumentando gradativamente ao longo dos anos.

Por outro lado, verificamos que a maioria dos docentes tem entre 31 e 41 anos de idade (60\%), fato este que concerne com a realidade brasileira, pois, conforme o Ministério da Educação (2014), 53,3\% dos docentes brasileiros estão na faixa etária de 25 a 40 anos e, no Amapá, isso equivale a 72,29\%, ficando evidente que a realidade dos docentes pesquisados não difere dos outros municípios amapaenses. Esses dados estão de acordo com o que apontou a Organização para a Cooperação e Desenvolvimento Econômico (OCDE) para o ano de 1999, em que, ao comparar o Brasil com a Coréia do Sul, verificou-se que os docentes, de modo geral, estão na faixa etária de 30 a 39 anos e atuam do Ensino Fundamental I ao Ensino Médio. Gatti (2010), por sua vez, constata que menos da metade do conjunto dos licenciandos no Brasil estão na faixa etária ideal (de 18 a 24 anos), idade esperada para a conclusão do curso superior, o que corrobora para a inserção tardia dos docentes no mercado de trabalho.

Portanto, há disparidade na formação docente nas diversas regiões brasileiras, mas concluímos que, apesar da região Norte ser evidenciada por possuir um dos menores índices de desenvolvimento da educação do país, o que tem se agravado por dificuldades de acesso ao ensino superior público, os docentes da escola pesquisada têm se inserido no mercado de trabalho na mesma faixa etária das outras regiões do país.

Os entrevistados, em sua maioria, são solteiros, sendo considerados "comprometidos" conjuntamente os casados, os amasiados e o viúvo (30\%). Quanto à formação, apenas 4,5\% $(\mathrm{n}=1)$ dos professores têm o ensino médio, 86,4\% $(\mathrm{n}=19)$ têm o ensino superior completo e $9,1 \%(\mathrm{n}=2)$ têm pós-graduação lato sensu, portanto, a maioria dos docentes pesquisados atendem o estabelecido na Lei de Diretrizes e Bases da Educação Nacional (BRASIL, 1996). Isso ocorre, provavelmente, devido a esses professores residirem a $27 \mathrm{~km}$ de Macapá, porém, esta não é a realidade da maioria das escolas de comunidades ribeirinhas da Amazônia amapaense.

Nesse sentido, analisando o sistema brasileiro de formação de professores, Mello (2000) aponta sua inadequação para colocar em prática o paradigma curricular requerido pela sociedade da informação e prescrito pela LDBEN, sugerindo caminhos e estratégias para a construção de modelos de formação, dentre eles a prioridade à formação de professores nos sistemas de fomento e financiamento.

Cabe lembrar também que, de acordo com dados do Ministério da Educação (2014), no período de 2009 a 2013 ocorreu um aumento de 7\% no número de professores da educação básica com ensino superior no Brasil, e que na região Norte este índice foi maior $(11,7 \%)$. No Amapá estes indicadores estiveram acima da média nacional (17\%), provavelmente devido às políticas de formação docente, por meio do Plano Nacional de Formação de Professores da Educação Básica (Parfor), implantado no ano de 2009, em cujo Plano dois professores entrevistados da Escola Estadual Francisco Filho concluíram sua formação inicial.

Nesse contexto, Gatti (2014) aborda que países como Tailândia, França, Chile, Estados Unidos, Inglaterra e Argentina têm desenvolvido, nas duas últimas décadas, políticas de formação docente, considerando a importância do professor na disseminação do conhecimento e da cultura. Para tanto, têm sido feitos investimentos em suas formações, de modo eficaz em todos os níveis de ensino. 
Outro ponto a ser analisado é a formação continuada, pois, de acordo com o Ministério da Educação (2014), no período de 2010 a 2014, houve um acréscimo de 6,7\% de professores com pós-graduação no Brasil e, na região Norte, foi de 5,1\%, mas, especificamente no Amapá, de $8,4 \%$. No entanto, no mesmo período, no Brasil, de 15.287 doutores e 45.067 mestres, a região Norte formou apenas 257 doutores e 1.921 mestres, que atuam como professores na educação básica. Este número é ainda menor quando se trata do Amapá, pois somente em 2011 o estado formou o primeiro professor doutor atuante na educação básica, e em 2013 chegou a ter 5 doutores e 51 mestres. Essa realidade é enfrentada na escola pesquisada, onde nenhum professor tem pós-graduação stricto sensu e, no decorrer das entrevistas, os professores verbalizaram que, embora pretendam fazer a pós-graduação, esta ainda não é realidade no momento.

Por outro lado, houve um acréscimo significativo de professores com pós-graduação lato sensu, provavelmente devido à facilidade de oferta pela rede privada de ensino. Um professor, por exemplo, comentou que conclui o curso de especialização na área da educação em apenas três meses, em uma dessas instituições. Esse fato é evidenciado pelo censo do IBGE (2010), o qual mostra que, no Amapá, apenas 1,2\% das pessoas que cursam o ensino superior estão em universidades públicas, uma vez que estas não têm se expandido para atender às demandas locais, o que contribui para o aumento de instituições privadas atuando na capital do estado.

No que se refere ao vínculo funcional dos professores pesquisados, verificamos que a maioria $(71,4 \%, \mathrm{n}=15)$ é do quadro permanente da Secretaria Estadual de Educação (Seed) do Amapá, oriundos do último concurso público realizado por este órgão no ano de 2012. Os professores temporários foram encaminhados via processo seletivo simplificado de contratação temporária, para atender às carências existentes na escola pesquisada, principalmente nas áreas de ciências exatas e biológicas.

Considerando o período 2009 a 2015, categorizamos os entrevistados com pouco tempo de atuação na docência - um período de 0 a 3 anos (40,9\%); com médio tempo - de 4 a 10 anos $(27,2 \%)$; e com longo tempo - de 11 a 20 anos de magistério (31,9\%).Consideramos com pouco tempo de atuação, 68,2\% dos professores, mostrando que a maioria dos entrevistados está na função há pouco tempo, sendo oriundos do último concurso da Seed realizado em 2012, o qual contribuiu para a diminuição da rotatividade de professores existente anteriormente.

Há apenas um professor com idade variando de 42 a 52 anos, e outro variando de 53 a 63 anos, e a professora com mais tempo de magistério (20 anos) possui 57 anos, e 10 dedicados à escola pesquisada, tendo a peculiaridade de ser a filha do fundador da Escola Estadual Francisco Filho. Em vista destes fatos, sugerimos que os professores aposentam-se precocemente e/ou optam por outras profissões, mais rentáveis financeiramente ou emocionalmente. Considerando que, atualmente, a idade mínima para a mulher se aposentar é de 60 anos e para o homem, 65, acreditamos que estes profissionais terão ainda aproximadamente 20 anos para se aposentar. No entanto, é necessário pensar urgentemente na formação de novos licenciandos para repor a demanda.

Três professores, por serem do Ensino Fundamental inicial, ministram todas as disciplinas; as doze disciplinas específicas são distribuídas entre os outros professores, contradizendo os dados do MEC (2014) que identificou, no ano de 2013 , que a maioria $(69,1 \%)$ dos professores do Amapá não atua em sua área de formação.

Cabe destacar que, no período de 2013 a 2014, os professores de Química e de Física na escola pesquisada assumiram suas turmas apenas no $3^{\circ}$ bimestre. Além disso, em 2014, houve a greve dos professores estaduais e a paralisação das atividades por problemas na instalação elétrica da escola, o que acarretou no atraso do calendário escolar. 


\subsection{Saberes docentes sobre meio ambiente}

"Conhecer as percepções de uma comunidade é essencial para construir um projeto político-pedagógico para a localidade envolvida". Essa afirmação foi proferida em uma palestra em 2014, pela Prof. ${ }^{a}$ Dra. Marília Tozoni-Reis, na qual abordou a necessidade de fazer um projeto de EA que identifique os problemas ambientais sentidos pela comunidade e os insira nas atividades pedagógicas da escola.

Pessano et al. (2013), acompanhando o mesmo raciocínio, ressaltam a importância do estudo das concepções para entendermos um determinado significado para um indivíduo, ou para um grupo de indivíduos, por meio da compreensão do sentimento e das atitudes de pessoas em relação àquele meio, porque esses significados poderão ser resultado dos interesses humanos sobre o objeto de estudo e podem favorecer a tomada de ação em busca da reconstrução do conhecimento, favorecendo novos valores e atitudes.

Por essa razão, inicialmente, dividimos os professores, didaticamente, nas três grandes áreas das Ciências: Humanas, Biológicas e Exatas (Tabela 1), a fim de verificar se havia uma percepção compartilhada entre professores da mesma área de conhecimento, sendo que os professores pedagogos foram colocadas na área de Ciências Humanas.

Tabela 1 - Percepções sobre meio ambiente dos professores, por área de conhecimento, da Escola Estadual Francisco Filho, comunidade do Anauerapucu - AP

\begin{tabular}{|c|c|c|}
\hline $\begin{array}{c}\text { Área de } \\
\text { conhecimento }\end{array}$ & $\begin{array}{l}\text { NP }= \\
\text { Número } \\
\text { de } \\
\text { Pessoas }\end{array}$ & Percepção sobre meio ambiente \\
\hline Ciências Biológicas & 4 & $\begin{array}{l}\text { Floresta, rios e queimadas. Falar sobre isso é um pouco complicado, mas } \\
\text { pela simbologia, calmaria e essência, é o cheiro e a tranquilidade da } \\
\text { floresta (Profs. } 1 \text { e } 3 \text { ). } \\
\text { Preservar, conservar e reciclar são palavras que lembram o meio } \\
\text { ambiente. As pessoas não têm consciência e jogam o lixo na rua, } \\
\text { principalmente os materiais plásticos (Profs. } 2 \text { e } 4 \text { ). }\end{array}$ \\
\hline Ciências Exatas & 3 & $\begin{array}{l}\text { O meio ambiente é a devastação que a gente vê, como o desmatamento e } \\
\text { a degradação (Profs. } 5 \text { e } 6 \text { ). } \\
\text { O meio ambiente é sustento do homem, porque se tem poluição não há } \\
\text { equilíbrio (Prof. } 7 \text { ). }\end{array}$ \\
\hline Ciências Humanas & 15 & $\begin{array}{l}\text { O meio ambiente é a natureza, a preservação e a reutilização, porque } \\
\text { somos os maiores destruidores de nossa natureza (Profs. } 8,9,10,11 \text { ). } \\
\text { A gente imagina que seja algo relacionado ao verde, à vegetação, à } \\
\text { mata, aos rios e às plantas (Profs. } 12,13,14,15,16,17) \text {. } \\
\text { O meio ambiente é o que você cuida, trata, e proporciona coisas boas, } \\
\text { que lhe proporciona uma vida saudável e tranquila (Profs. } 18,19 \text { ). } \\
\text { O meio ambiente é procurar meios sustentáveis de vida, enquanto ser } \\
\text { humano, para que o meio ambiente se torne sustentável (Prof. 20). } \\
\text { É a valorização do espaço que você passa a respeitar, porque eu só posso } \\
\text { cuidar daquilo que eu amo (Profs. } 21,22 \text { ). }\end{array}$ \\
\hline
\end{tabular}

Aparentemente, percebemos que a maioria dos professores, independentemente da área de conhecimento, tinham uma percepção romântica/naturalista de meio ambiente. Ao tentarmos desmembrar o discurso em definições curtas, verificamos outras possibilidades (Tabela 2). 
Tabela 2 - Percepções sobre meio ambiente, distribuídas por categorias de análise, de professores (Profs.) da Escola Estadual Francisco Filho, comunidade do Anauerapucu - AP

\begin{tabular}{|c|c|}
\hline Categorias & Palavras-chave \\
\hline Romântica/Naturalista & $\begin{array}{l}\text { Floresta, rios, calmaria e essência, cheiro, paisagem e tranquilidade (Profs. } 1 \text { e } \\
\text { 3); bonitinho (Prof. 2); natureza (Profs. 8, 9, 10, 11); verde, vegetação, mata, } \\
\text { rios e plantas (Profs. 12,13,14,15, 16, 17). }\end{array}$ \\
\hline $\begin{array}{l}\text { Antropocêntrica/ } \\
\text { Utilitarista/ } \\
\text { Preservacionista }\end{array}$ & $\begin{array}{l}\text { Preservar, conservar e reciclar (Profs. } 2 \text { e } 4 \text { ); sustento/sobrevivência do homem } \\
\text { (Profs. 5, 7); preservação e reutilização (Profs. 8, 9, 10,11); você cuida, trata e } \\
\text { proporciona vida saudável e tranquila (Profs. 18, 19); procurar meios } \\
\text { sustentáveis de vida, para que o meio ambiente se torne sustentável (Prof. 20); } \\
\text { valorização e respeito pelo espaço, porque eu só posso cuidar daquilo que eu } \\
\text { amo (Prof. 21). }\end{array}$ \\
\hline Socioambiental & $\begin{array}{l}\text { Queimadas (Prof. 1); pessoas não cuidam (Prof. } 3 \text { ); jogam lixo e materiais } \\
\text { plásticos em locais inadequados (Profs. } 1,2 \text { e } 4 \text { ); devastação, desmatamento, } \\
\text { degradação (Profs. } 5 \text { e 6); somos os maiores destruidores de nossa natureza } \\
\text { (Profs. } 8,9,10,11) \text {. }\end{array}$ \\
\hline
\end{tabular}

Verificamos que os professores têm uma visão romântica/naturalista, antropocêntrica/utilitarista/preservacionista e/ou socioambiental, não se encaixando em uma categoria apenas reducionista, a qual se refere aos aspectos estritamente físicos, químicos e biológicos, mas também não percebem o meio ambiente de forma abrangente, o qual envolve os aspectos naturais e os resultantes das ações antrópicas, além da interação de todos os fatores, incluindo os sociais, econômicos e culturais. Destacamos as falas dos professores para ilustrar a presença das três categorias:

A gente imagina logo que o meio ambiente seja algo relacionado ao verde, vegetação, mata, plantas, árvores, né? Isso é algo que a gente imagina logo de uma forma positiva, né? Como aquilo bonitinho e tudo mais (Prof. 2). Percepção reducionista.

O meio ambiente é isso, tem... às vezes têm pessoas que não cuidam, e que, por exemplo, não estão ligando para esses avanços que tem... e não tenho assim, muito o que falar, não sou muito ligada. Mas sempre que posso eu vou pro terreno, e fico lá e, pra mim, é como se fosse respirar outro ar, ficar admirando aquela paisagem, porque eu gosto (Prof. 3). Percepção romântica/naturalista e socioambiental.

A floresta, porque o verde é primordial na nossa vida. Eu entendo assim, que a floresta... se não tivesse uma floresta a gente tinha muito calor né, e os rios é que é um meio de sobrevivência, porque através dos rios a gente pesca, a gente nada, ainda mais os ribeirinhos aqui. (Prof. 5). Percepção romântica/naturalista e antropocêntrica/utilitarista/preservacionista.

Na realidade, mesmo em uma percepção reducionista (como exemplificado na fala do professor 2), quando solicitados maiores esclarecimentos, indicou ser também romântica/naturalista. Por essa razão, essa percepção não foi posta na Tabela 2, uma vez que, ao ressaltar os fatores extrínsecos ambientais, não há como excluir o homem do ambiente em que vive e interage.

Alguns professores, nos depoimentos a seguir, expõem respostas mais elaboradas: 
Isso tudo envolve o meio ambiente. É o local que vivemos, é geralmente tudo o que precisamos, temos em nossa volta, preservar para manter o que ainda nos resta, pois tudo está se acabando, somos os maiores destruidores da nossa grande natureza. Dentro disso têm os recursos que servem de reutilização: através do que, para nós, não serve, outros reutilizam tornando coisas que podem ser aproveitadas (Prof. 18).

\begin{abstract}
Humanidade no sentido do ser humano, né? Porque eu acho que a questão da conscientização começa por nós, enquanto seres racionais de responsabilidade por esse meio ambiente. A globalização na questão do meio ambiente vem muito que hoje o mundo tá muito avançado, a gente vê tantas informações e às vezes essas informações nem são utilizadas em prol do meio ambiente. A sustentabilidade, no caso, é fundamental pra prevalência desse meio ambiente, procurar meios sustentáveis de vida, enquanto ser humano, pra que esse meio ambiente se torne sustentável, de alguma forma, pela reciclagem. (Prof. 6).
\end{abstract}

Quando se fala em meio ambiente, algum tempo atrás, ele só se relacionava à floresta, só à poluição, desmatamento. Hoje já é visto com outros olhos, já se insere tudo, quando se fala em meio ambiente, não só a natureza (Prof. 9).

O problema é que essas falas não se configuram como uma percepção abrangente/holística de meio ambiente, uma vez que se restringe a "isso tudo envolve o meio ambiente"; "humanidade no sentido do ser humano" e "já se insere tudo", sem conseguir deslanchar e incorporar os aspectos socioeconômicos e culturais, embora tenha ocorrido a tentativa de uma visão globalizante dos aspectos ambientais relacionado à sustentabilidade e à globalização. Mas é perceptível um distanciamento da compreensão da complexidade ambiental, como resultado da dinâmica do sistema natural e das interações entre sistema social e natural, de acordo com Santos e Imbernon (2014) e Bezerra, Feliciano e Alves (2008).

Se quisermos extrapolar e deduzir que a afirmação dos professores de que meio ambiente é tudo significa "tudo que nos rodeia" - o que nos reporta apenas aos elementos naturais -, lembramo-nos de que estes elementos do meio natural sofrem intervenções humanas, e estas interferem no modo e na qualidade de vida dos indivíduos. Parece-nos coerente, mas consideramos que os professores não conseguem fazer estas interações e inferências. Além disso, pela comunidade de Anauerapucu não estar inserida em um meio urbano, os professores em nenhum momento se lembraram de incluir o ambiente construído como parte do meio ambiente.

Constatamos nas entrevistas e nas sessões de grupo focal que os docentes não se colocam como agentes do meio, mas sempre se reportavam a um educando, vizinho ou a uma situação divulgada nos telejornais, mas não às suas vivências cotidianas. Logo, podemos afirmar que a abrangência de seus conhecimentos profissionais e pessoais não são, neste momento, suficientes para reconhecer o meio ambiente como um conteúdo existencial e conceitual com suas múltiplas dimensões.

Parece difícil para os professores entrevistados, uma compreensão em termos de "harmonia" ou "desarmonia" ecológica para uma percepção mais abrangente do significado de meio ambiente para a existência humana, apreendendo este conceito como uma interação complexa das relações socioambientais e culturais, dada a dificuldade de incorporarem espontaneamente questões que perfazem a totalidade desta discussão.

A falta de uma visão abrangente/holística de meio ambiente não é observada apenas entre os professores pesquisados, mas por paraenses (DANTAS; NAKAYAMA; SANTANA, 2009; DANTAS; SANTANA; NAKAYAMA, 2012; SILVA et al., 2012), ou cartunistas nacionais e internacionais (ALMEIDA et al., 2010), e frequentadores da $1^{\circ}$ Salão de Humor da Amazônia, em sua maioria paraenses (ALMEIDA et al., 2014); também de professores da 
região metropolitana de Manaus (COSTA et al., 2012), de São Paulo (RODRIGUES et al. 2012), de Recife (BEZERRA; FELICIANO; ALVES, 2008) e Porto Rico, no estado do Paraná (MAGALHÃES JÚNIOR; TOMANIK, 2013), ao identificarem uma visão dissociada do ser humano com seus espaços de interação.

Em outro esforço para tentarmos compreender a percepção dos professores de diferentes áreas de conhecimento da escola estudada, sobre meio ambiente e as principais problemáticas socioambientais existentes na área de estudo, lhes solicitamos que caracterizassem em três palavras (substantivos), em ordem de importância, o que entendem por meio ambiente (Tabela $3)$.

Tabela 3 - Percepções docentes sobre meio ambiente distribuídas por palavras-chave, na Escola Estadual Francisco Filho, Santana - AP

\begin{tabular}{|c|c|c|}
\hline Palavras-chave & Número absoluto & Frequência de ocorrência (\%) \\
\hline \multicolumn{3}{|c|}{ Primeira opção } \\
\hline Natureza (rios e florestas) & 12 & 54,6 \\
\hline Preservação ambiental & 5 & 22,8 \\
\hline Sustentabilidade & 2 & 9,1 \\
\hline Reutilização & 1 & 4,5 \\
\hline Tranquilidade & 1 & 4,5 \\
\hline Humanidade & 1 & 4,5 \\
\hline \multicolumn{3}{|c|}{ Segunda opcão } \\
\hline Problemas ambientais & 6 & 27,4 \\
\hline Natureza (rios e florestas) & 4 & 18,2 \\
\hline Preservação ambiental & 4 & 18,2 \\
\hline Tranquilidade & 2 & 9,1 \\
\hline Saúde & 2 & 9,1 \\
\hline Educação ambiental & 1 & 4,5 \\
\hline Família & 1 & 4,5 \\
\hline Globalização & 1 & 4,5 \\
\hline Consciência & 1 & 4,5 \\
\hline \multicolumn{3}{|c|}{ Terceira opcão } \\
\hline Humanidade & 4 & 18,2 \\
\hline Consciência & 4 & 18,2 \\
\hline Tranquilidade & 4 & 18,2 \\
\hline Preservação ambiental & 2 & 9,1 \\
\hline Reutilização & 3 & 13,7 \\
\hline Natureza (rios e florestas) & 2 & 9,1 \\
\hline Educação Ambiental & 1 & 4,5 \\
\hline Saúde & 1 & 4,5 \\
\hline Sustentabilidade & 1 & 4,5 \\
\hline
\end{tabular}

Dos 22 professores que atuam na Escola Estadual Francisco Filho, sobressaíram os elementos da natureza, com destaque para os rios e florestas $(54,6 \%)$ como a primeira opção. Ao somá-la à segunda e à terceira opção, a natureza totaliza $81,9 \%$ das citações. Esperávamos essa lembrança por serem as características da comunidade de Anauerapucu, localidade onde trabalham com uma exuberante floresta tropical e recursos hídricos, contexto típico da região amazônica brasileira, e por haver ações antrópicas sobre este recurso natural (preservação ambiental, problemas ambientais, consciência, dentre outras opções).

A concepção romântica/naturalista sobre o meio ambiente manifestada pelos professores aparece de forma muito tímida em palavras como globalização, sustentabilidade, humanidade e consciência, porém, atrelada ao mito da natureza intocada, o que se aproxima da 
vertente ecológica presente nos livros didáticos, em que modelos tradicionais ainda persistem, demonstrando que as reflexões relacionadas à realidade científica sobre a temática ainda são negligenciadas na escola (REIGOTA, 2010).

Essa visão predominante entre os docentes, que separa o ser humano do meio ambiente, colocando-o como mero observador, sem laços de pertencimento e de responsabilidade (DUARTE et al., 2014; GUERRA; GUIMARÃES, 2007; GOUVEA, 2006; RODRIGUES, OLIVEIRA; QUEIROZ,, 2013;), denota distorções de caráter epistemológico na leitura do mundo e são coerentes com uma concepção fragmentada de aprendizagem e de formação inicial dos docentes pesquisados.

Cabe lembrar que, embora na formação de professores esteja previsto que "a dimensão ambiental deve constar nos currículos de formação de professores, em todos os níveis e em todas as disciplinas", no Art. 11 da Lei 9.795/1999 (BRASIL, 1999) há déficits na formação inicial docente, porque a questão ambiental é deixada de lado e, desta forma, tem repercutindo diretamente na maneira de o professor compreender a relação homem-natureza (BOER; SCRIOT, 2011; MATOS, 2009; TEIXEIRA; TORALES, 2014), por esta razão, consideramos que os professores estão contribuindo para a distorção da conceituação de meio ambiente na educação formal.

Gatti et al. (2011) afirmam que a formação inicial de professores tem importância ímpar, por criar as bases sobre as quais esse profissional tenha condições de exercer as atividades educativas, e Cebrián e Junyent (2015) afirma que os professores com nível universitário têm liberdade para ensinar e pesquisar sobre suas áreas de interesse, podendo ser um facilitador para a compreensão da relevância dada as questões socioambientais na prática docente.

Nesse sentido, é relevante questionarmos a maneira como tem sido trabalhada a questão ambiental na formação inicial do professor, pois a maioria dos entrevistados é recém-formado e, conforme os relatos, este assunto não integrou o currículo da formação dos professores pesquisados, não havendo discussão a respeito na graduação; e o mais intrigante é o fato de estarmos na Amazônia e a maioria da população depender diretamente das relações sociais, políticas, econômicas, histórica e cultural com a natureza.

Esses resultados são preocupantes, pois a dimensão socioambiental apontada como fundamental em se tratando de educação escolar ganhou destaque após a ECO-92, mas, pelo que constatamos, ainda não ocorreu a capacitação e/ou sensibilização dos docentes para as questões socioambientais em suas práticas educativas.

Guimarães (2011) afirma que os professores têm uma percepção de que o valor da "importância da natureza" já está bem difundido e efetivamente aceito na sociedade em geral, o que não significa uma ação preservacionista dessa sociedade, de acordo com percepções docentes, em Xerém - Rio de Janeiro. Entretanto, esta não é a realidade da área de estudo, pois verificamos que os professores de Anauerapucu ainda possuem uma visão fragmentada da relação homem-natureza e a percepção de preservação e conservação ainda é predominante.

Cabe salientar que compreender o conceito de percepção ambiental dos professores não tinha apenas a conotação de conhecer as representações que melhor correspondem à realidade da comunidade de Anauerapucu, mas elucidar as perspectivas científicas, culturais, políticas e sociais, inerentes ao emprego deste conceito.

Neste contexto, os problemas ambientais já haviam aparecido ao serem tratadas as percepções sobre meio ambiente, mas ao questionarmos os docentes sobre os principais problemas socioambientais existentes na comunidade, destacaram, além do lixo, saneamento básico, desmatamento/queimada e poluição do rio, considerados como problema ambiental da escola e da comunidade e os problemas inerentes à escola: falta de água potável, estrutura física precária e falta de consciência. Como problemas sociais citaram: gravidez precoce, alcoolismo, 
ausência dos pais, prostituição, drogas, vias de acesso à escola precário, violência e desemprego. Vários desses problemas nós constatamos nas observações in loco.

Destacamos que os problemas elencados pelos entrevistados se pautaram no que vivenciam na escola e no que os educandos comentam em sala de aula, porque apenas dois professores moram na localidade. Assim, a maioria dos professores afirmam não conhecer a comunidade, tratando-a como "aí pra trás", então, a relação com os comunitários só ocorre nos plantões pedagógicos, ocasionando distanciamento dos professores das vivências, da história e da cultura local.

Essa postura está de acordo com Rezende Silva e Silveira (2009) ao afirmar que a maioria dos professores das áreas rurais reside em áreas urbanas, ficando nestas áreas apenas no período letivo e, mesmo assim, de segunda a sexta-feira, e fora do período letivo, os docentes retornam para o centro urbano, ficando divididos entre o meio urbano e o rural.

Portanto, os professores só vão à comunidade do Anauerapucu para ministrar suas aulas e retornam à sede municipal no mesmo dia, inviabilizando laços afetivos com a comunidade, $\mathrm{o}$ que de acordo Tuan (1980), reflete na estreita relação entre vivência e tempo, pois não é possível adquirir senso de lugar pelo simples ato de cruzar por ele, supondo que o nativo tem uma complexa e derivada percepção do meio onde está inserido, diferente do "visitante" ou do "passante".

Assim, os docentes percebem os problemas ambientais como lixo, redução da biodiversidade, falta de água, dentre outros, citando, mas não desenvolvendo, temas sociais locais, deixando de lado as relações professor-aluno e professor-comunidade, que são essenciais para mudanças de valores e atitudes. Não é sem razão que Bezerra et al. (2010) afirmam que o caminho para se estabelecer parcerias pode ser uma experiência significativa no ensino tanto dentro como fora da escola.

\section{Considerações Finais}

Os professores da Escola Estadual Francisco Filho são, em sua maioria, jovens e solteiros, com ensino superior completo. Destes, $10 \%$ têm pós-graduação lato sensu. Esses dados estão de acordo com a tendência mundial de que os jovens estão investindo em suas carreiras, visando o mercado de trabalho cada vez mais competitivo e adiando, assim, a opção de casar e de gerar filhos.

Por terem investido em sua formação superior, a maioria tem menos de dez anos de serviço, sendo que $25 \%$ tem menos de um ano de magistério; dos que possuem mais de 10 anos, alguns, provavelmente, fizeram sua graduação e/ou pós-graduação lato sensu quando já estavam ministrando aulas para o ensino básico. Consequentemente, por possuírem formação superior, a maioria dos professores atua no Ensino Fundamental II e/ou Ensino Médio.

Os professores comentaram que não conheciam a comunidade porque passavam o dia na escola e, no final da tarde, precisam estar preparados para não perder a condução que os levariam para a balsa, para retornarem às suas residências na cidade (sede do município de Santana). Os problemas ambientais da escola/comunidade acabaram a ser reduzidos ao lixo (na escola e seu entorno, cursos hídricos), à escassez de recursos naturais, à diminuição da biodiversidade, dentre outros, em detrimento das relações sociais que são de extrema importância para mudança de valores e de atitudes.

No entanto, alguns professores, no grupo focal, manifestaram-se envergonhados por não conhecerem melhor a realidade local. Portanto, achamos esta postura positiva, porque à medida que um novo olhar é despertado, pode ser possível a transformação: a percepção dos espaços com novas imagens e valores adquiridos na interação com o meio ambiente, de forma 
mais consciente e, neste envolvimento, a ação para tentar resolver ou minimizar os problemas ambientais.

\section{REFERENCIAS}

ALMEIDA, M. L. et al. Percepção ambiental dos expositores do $1^{\circ}$ Salão de Humor da Amazônia: relato de caso. Revista Cocar, Belém, v. 4, n. 8, p. 91-98, 2010.

ALMEIDA, M. L. et al. Percepções de Amazônia: o olhar do público no $1^{\circ}$ Salão de Humor da Amazônia. Educação Ambiental em Ação, Juiz de Fora, n. 49, p. 1-12, 2014.

ANDRADE, M.; AMORIN, V. Grupo focal: a pesquisa com foco na interação dos sujeitos. Belém: Eduepa, 2010.

BEZERRA, T. M. O.; FELICIANO, A. L. P.; ALVES, Â. G. C. Percepção ambiental de alunos e professores do entorno da Estação Ecológica de Caetés - Região Metropolitana do Recife-PE. Biotemas, Florianópolis, v. 21, n. 1, p. 147-160, 2008.

BEZERRA, Z. F. et al. Comunidade e escola: reflexões sobre uma integração necessária. Educar em Revista, Curitiba, n. 37, p. 279-291, 2010.

BOER, N.; SCRIOT, I. Educação ambiental e formação inicial de professores: ensino e concepções de estudantes de pedagogia. Revista Eletrônica do Mestrado em Educação Ambiental, Rio Grande, v. 26, p. 46-60, 2011.

BRASIL. Lei n 9.394, 20 de dezembro de 1996. Estabelece as diretrizes e bases da educação nacional. Diário Oficial da União, Brasília, DF, 23 dez. 1996.

BRASIL. Lei $n^{\circ}$ 9.795, de 27 de abril de 1999. Dispõe sobre a Educação Ambiental, institui a Política Nacional de Educação Ambiental e dá outras providências. Diário Oficial da União, Brasília, DF, 28 abr. 1999. p. 1.

BELLENGER, D. N.; BERNHARDT, K. L.; GOLDSTUCKER, J. L. Qualitative research in marketing. Chicago: American Marketing Association, 1976. (Qualitative Research Techniques: focus group interviews).

BORGES, C. D.; SANTOS, M. A. Aplicações metodológicas da técnica de Grupo Focal: fundamentos metodológicos, potencialidades e limites. Revista Spagesp, Ribeirão Preto, v. 6, n. 1, 2005.

CEBRIÁN, G.; JUNYENT, M. Competencies in education for sustainable development: exploring the student teachers' views. Sustainability, Basel, v. 7, p. 2768-2786, 2015.

COSTA, J. R. et al. A percepção ambiental do corpo docente de uma escola pública rural em Manaus (Amazonas). Revista Brasileira de Educação Ambiental, Rio Grande, v. 7, p. 63-67, 2012.

DANTAS, O. M. S.; NAKAYAMA, L.; SANTANA, A. R. Abordagens de ambiente na ótica de professores de Ciências. Revista Brasileira de Educação Ambiental, Rio Grande, n. 4, p. 107-114, 2009.

DANTAS, O. M. S.; SANTANA, A. R.; NAKAYAMA, L. Teatro de fantoches na formação continuada docente em Educação Ambiental. Educação e Pesquisa, São Paulo, v. 38, n. 3, p. 711-726, 2012.

DUARTE, V. S. et al. A formação do educador ambiental em debate: uma perspectiva interdisciplinar sobre o perfil deste profissional. Pesquisa em Educação Ambiental, São Paulo, v. 9, n. 2, p. 98-113, 2014. 
FLICK, U. Introdução a pesquisa qualitativa. Porto Alegre: Artmed, 2009.

GATTI, B. A. A formação de professores no Brasil: características e problemas. Educação e Sociedade, Campinas, v. 31, n. 113, p. 1355-1379, 2010.

GATTI, B. A. A formação inicial de professores para a educação básica: as licenciaturas. Revista USP, São Paulo, n. 100, p. 33-46, 2014.

GATTI, B. A.; BARRETO, E. S. S. Professores: aspectos de sua profissionalização, formação e valorização social. Brasília, DF: Unesco 2009.

GUERRA, A. F. S.; GUIMARÃES, M. Educação ambiental no contexto escolar: questões levantadas no GDP. Pesquisa em Educação Ambiental, São Paulo, v. 2, n. 1, p. 155-166, 2007.

GUIMARÃES, M. A formação de educadores ambientais. Campinas: Papirus, 2011.

GUNTHER, H. Pesquisa qualitativa versus Pesquisa quantitativa: esta é a questão. Revista Psicologia: Teoria e Pesquisa, Brasília, DF, v. 22, n. 2, p. 201-210, 2006.

INSTITUTO BRASILEIRO DE GEOGRAFIA E ESTATÍSTICA. Censo Demográfico. Brasília, DF, 2010. Disponível em: 〈https://goo.gl/ISkJF>. Acesso em: 3 abr. 2016.

INSTITUTO NACIONAL DE ESTUDOS E PESQUISAS EDUCACIONAIS ANÍSIO TEIXEIRA. Estudo exploratorio sobre o professor brasileiro. Brasília, DF: MEC, 2009. Disponível em: http://portal.mec.gov.br/dmdocuments/estudoprofessor.pdf. Acesso em: 16 jan. 2018.

LEFF, E. Discursos sustentáveis. São Paulo: Cortez, 2010.

MAGALHÃES JÚNIOR, C. A. O.; TOMANIK, E. A. Representações sociais de meio ambiente: subsídios para a formação continuada de professores. Ciência \& Educação, Bauru, v. 19, n. 1, p. 181199, 2013.

MELLO, G. N. Formação inicial de professores para a educação básica: uma (re)visão radical. São Paulo em Perspectiva, São Paulo, v. 14, n. 1, p. 98-110, 2000.

MINISTÉRIO DA EDUCAÇÃO. Censo escolar 2014. Brasília, DF, 2014. Disponivel em: <https://goo.gl/e34sFW>. Acesso em: 6 abr. 2016.

MIRANDA, D. J. P. Educação e percepção ambiental: o despertar consciente do saber ambiental para a ação do homem na natureza. Revista Eletrônica do Mestrado em Educação Ambiental, Rio Grande, v. 19, 2007.

PESSANO, E. F. C. et al. Percepções socioambientais de estudantes concluintes do ensino fundamental sobre o rio Uruguai. Revista Ciências \& Ideias, Niterói, v. 4, n. 2, p. 1-23, 2013.

REIGOTA, M. O que é educação ambiental. São Paulo: Brasiliense, 2009.

REIGOTA, M. Meio ambiente e representação social. São Paulo: Cortez, 2010.

REZENDE, C. N. V.; SILVA, S. L. C.; SILVEIRA, T. C. Percepção ambiental e a prática docente nas escolas do meio rural do município de Itapetinga-BA. Revista Eletrônica do Mestrado em Educação Ambiental, Rio Grande, v. 23, p. 493-514, 2009. 
RODRIGUES, M. L. et al. A percepção ambiental como instrumento de apoio na gestão e na formulação de políticas públicas ambientais. Saúde e Sociedade, São Paulo, v. 21, supl. 3, p. 96-110, 2012.

RODRIGUES, J. N.; OLIVEIRA, A. L.; QUEIROZ, E. D. Universidade e formação de educadores ambientais críticos. Educação: Teoria e Prática, Rio Claro, v. 23, n. 42, p. 90-105, 2013.

SANTOS, J. A. E.; IMBERNON, R. A. L. A concepção sobre "natureza" e "meio ambiente" para distintos atores sociais. Terrae Didática, Campinas, p. 151-159, 2014.

SANTOS-FILHO, J. C.; GAMBOA, S. S. (Orgs.). Pesquisa educacional: quantidade-qualidade. São Paulo: Cortez, 2002.

SILVA, L. C. et al. Projeto Sábado Esperto: educação ambiental no Bosque Rodrigues Alves, Jardim Botânico da Amazônia, Belém - PA. Educação Ambiental em Ação, Juiz de Fora, n. 40, p. 1-15, 2012.

TEIXEIRA, C.; TORALES, M. A. A questão ambiental e a formação de professores para a educação básica: um olhar sobre as licenciaturas. Educar em Revista: Edição Especial, Curitiba, n. 3, p. 127-144, 2014.

TUAN, Y. Topofilia: um estudo da percepção, atitudes e valores do meio ambiente. São Paulo: Difel, 1980.

YIN, R. K. Estudo de caso: planejamento e métodos. Porto Alegre: Bookman, 2010. 